\title{
Research on System Culture of Patriarchal Clan of the Area South of the Yangtze River in the Ming and Qing Dynasties
}

\author{
Lixing Xu \\ China University of Political Science and Law, Beijing, 100000, China
}

Keywords: Family system, Clan rule, Ming and Qing Dynasties, Jinhua

\begin{abstract}
The elites in the Yuan Dynasty were not in a good way to participate in politics, and the elite began to take the main position of patriarchal clan system. The clan system to shift the public, autonomy in the Ming Dynasty, through the past genealogy system designed to build the temple, repair spectrum, formulate rules together, strengthen political nature. The Qing Dynasty further reduced the clan. The Ming and Qing Dynasties literati by building clan people, maintain social order, caused by this process and organization of the clan. During the Ming and Qing Dynasties, clan system had strict hierarchy, adjusted patriarchal property relations, protected patriarchal marriage and inheritance system, and maintained patriarchal social order. The clan field system clan South developed, not only relieving people, and support people reading through the imperial examination to the court and to transport personnel, politics closely. The construction of patriarchal clan system in Ming and Qing Dynasties embodies the system of gathering, collecting, preserving and living the Chinese people, exploring and pursuing governance experience is worth studying. In the central part of Zhejiang Province, Jinhua pays great attention to the correction of the ancient times, and attracts many scholars and scholars to participate in it. It has preserved many precious documents, which is typical and has higher research value. This paper intends to summarize and summarize the research literature of patriarchal culture in the Jiangnan during Ming and Qing dynasties.

In the late Ming and early Qing Dynasty, Gu Yanwu, a thinker, said, "the decrees and decrees are in the right place and are full of customs.".Chinese traditional patriarchal clan system, patriarchal culture, after the Yuan Ming and Qing Dynasties practice, highly concentrated on political and institutional China intellectual elite, is the construction of moral personality, cohesion and effective the important social system, it can be found that many of the ancients of social governance wisdom. Jinhua, located in the middle part of Zhejiang Province, is the important city of ancient Eastern Zhejiang school. Many universities, such as Song Lian, Lv Zuqian and he yuan, have directly participated in the local clan system practice, which can be regarded as a typical representative of the patriarchal clan law culture in the south of the Yangtze river. In the past dynasties, the region paid much attention to the correction of records, often with a surname and dozens of repairs, and attracted the participation of many scholars and scholars, and preserved many ancient documents of great value. Family in Jinhua is a long history, but the study is still lack, need to be excavated. In order to better study and understand the patriarchal clan system and culture of Jinhua in Ming and Qing Dynasties, this paper intends to make a summary of the research on patriarchal clan system in the academic circles.
\end{abstract}

\section{General Situation of Research}

Liu Yanyuan "since 1990 Jiangnan clan history review", and "Chang Jianhua twentieth Century Chinese clan research" review of literature, the main research Chinese clan in twentieth Century, research on clan economy, clan culture, clan society, clan history has made more comprehensive order. 
General history research, Mr. Lv Simian started their studies on the history of the clan system, China he wrote "(Zhongshan publishing house, 1929, after Lu" Chinese income system history ", Shanghai Education Press, 1985 Edition) is the first Chinese clan history. In view of the evolution of Chinese family society (central bookstore, 1944), the author studied the family of Zhou, song and Qing Dynasties from the sociological perspective, and compared the ancient and modern family systems of the three dynasties. Xu Yangjie's book "the history of Chinese family system" (people's publishing house, 1992), in accordance with their own point of view, the Chinese family history has been phased. Feng Erkang "Chinese ancient clan and ancestral temple" is a typical clan system in pre Qin thought, namely the aristocracy era; Qin Tang is noble, gentry clan times; song is the bureaucrat clan system in Ming and Qing Dynasties era; the gentry clan system is rich and popular clan era. Ke Changji "China ancient rural commune history" (Zhongzhou ancient books publishing house in 1988) is not a book but there is a considerable length of clan history, especially after the song discusses their problems. Xu Yangjie's study of the clans after Song Dynasty mainly focused on his collection of essays, the history of Song Ming's family system (Zhonghua Book Company, 1995).

Ke Changji's view of patriarchal clan system (the second period of Chinese social economic history), 1985, discusses the content, type, clan field and decline of patriarchal clan system after song dynasty. Li Wenzhi "on the Ming and Qing Dynasties clan system" ("China Academy of Social Sciences Institute of Economic Research of" fourth series, 1983) discussed the Ming and Qing Dynasties clan system. Han Dacheng "in the Ming Dynasty clan and feudal autocracy" ("historical review" second series, qilushushe 1981) is the Ming Dynasty clan system theory. Feng Erkang in the "people's life" ("the patriarchal society of social life" the fifth chapter, Tianjin people's Publishing House in 1990) is discussed under the management of people and ancestral life, the relationship between hall and government; and the "Qing Dynasty clan system features" ("Social Science Front" in 1990 third). Money Hangzhou, bearing the "seventeenth Century Jiangnan social life" (Zhejiang people's publishing house, 1996) the second chapter "Jiangnan clan and social life", discusses the clan relief, education, power and other issues.

Feng Erkang, co-author of "China clan society" (Zhejiang people's publishing house, 1994), the three criteria proposed the development history of the clan, the clan leadership lies in what kind of social group in the hands of the people of the identity, internal structure and members of clan, patriarchal clan changes principle in life. Tao Xisheng in "marriage and family" in a Book (the commercial press in 1934) is discussed under the patriarchal and patriarchal marriage, women and family, father and son, the formation of the decomposition, the decline of the family system, the stage said. Chang Jianhua wrote "the annals of lineage" (Shanghai people's publishing house, 1998), taking into account the structure, form and function of the patriarchal clan system, and comprehensively and systematically discussed the basic content of the patriarchal clan system in china. Li Wenzhi "Chinese feudal land relationship with the patriarchal clan system" ("historical research" in 1989 fifth) is a variation of clan system development. Thinking on "governance" clan system ("Qing Dynasty essays" Zhonghua fourth series, 1982) that the genealogy, ancestral hall, heads of three as the core, to the clan field as a means of forming since Song Dynasty clan clan, to the Qing development heyday.

Japanese scholar Niida Se "China rural family", Makino Xun "research" Chinese family system and the "modern Chinese clan research", "China Kato often Xian ancient family system research", Taka Akigoro's "China genealogical research", this problem also has in-depth study.

\section{Origination, Features and Functions}

Su Li Yuan Dynasty "local elite and the grassroots society in Jiangnan area as the research center" this way because the elite political participation of the poor, the elite gradually began to assume the clan patriarchal system's main body status, through their individual efforts, as the Zong Fazong family system has made many contributions in the continued development and change of the Yuan Dynasty. Open to people of the clan system, autonomous precedent in the Ming dynasty. Cao Kai "on the value orientation and function" Chinese ancient family law that was built in the early Ming Dynasty Hongwu village when the "Christian Proclamation", reformed in the Zhengde period Wang 
Yangming, rebuilt and popularized in Jiajing and Wanli period. Li Wenzhi "in the Ming Dynasty the patriarchal clan system forms and grassroots action on feudal ownership is the ultimate source of" change of patriarchal clan system and the development that the development and change of the Ming Dynasty more than 200 years of patriarchal clan system is mainly reflected in two points, one is the abolition of the temple built and after offering generation constraints, strengthen the political nature of the two. In the past re Xiuzhuan genealogy system designed to build the temple, repair spectrum, formulate rules together.

Chang Jianhua: "the clan and the epitome of the late Ming Dynasty customs and social changes in Zhejiang -- Taking Yuyao Jiangnan family" in Zhejiang Yuyao Xu Xu Jiangnan family, that when the Ming Dynasty Jiajing Xu Tianze concluded the changes of Customs for people in pursuit of "desire", "righteousness" ethical political rule, "desire" show "Lee" is undoubtedly a great impact on society. The literati by building clan people, maintain social order, caused by this process and organization of the clan. Liu Zongtang "in the Qing Dynasty clan regulations cultural connotation and social function" that the clan system has a strict hierarchy, adjust the patriarchal patriarchal marital property relations, the protection and inheritance system, maintain the patriarchal social order function. Analysis of the expansion and the reasons of Xu Huaan "the Qing Dynasty clan" ("Qing" of 1992 fourth) due to expansion of the clan development in Qing Dynasty are also discussed.

Hangzhou money "on the surname associations organization geopolitical nature" ("Shi Lin" in 1998 third) pointed out, jointly organized by United formation is not the so-called "joint family", but a loose network of geographical name. Xu Maoming no "clan" and "Jiangnan Jiangnan" clan "of the famous Japanese scholar Professor Hajima Nobutoshi" Jiangnan "clan" without a proposed "the genealogy is often to presumption of kinship to unite the same surname, is for the analysis of a product of the imagination of the view. Where in the "New Deal" (and alternative income "New Deal" in annotating, 1901) said: "gentlemen elder no official name, but a real officer. This is the clan rule." Lin Yaohua (1936) published a study of Chinese lineage village from the perspective of Anthropology (ninth volume of Sociology), 1937, and proposed a new method of studying clans.

\section{Attitude of Government to Patriarchal Clans}

As an important social unit China history, dynasties take different attitudes towards the relationship between clan, clan and the dynasty was also with the potential of moving state. The development of the clan system Chang Jianhua "Songyuan under the imperial examination system" ("China clan society" chapter third) and "clan Chi" (Shanghai people's Publishing House in 1998) in the relevant part of the overall discussion to the relationship between the clan and the dynasties of.

$\mathrm{Xu}$ Xiaowang "on the relationship between the government and the clan of Ming and Qing Dynasties" ("Journal of Xiamen University 1985 third) a comprehensive analysis of the government and clan relationship, especially on the destruction of the rule of law and the government of the feudal clan clan blow. Clan was an important social unit in Qing Dynasty. Clan with certain influence played a certain role in the Qing Dynasty, and the government set up special ethnic groups to control and restrain the development of clan. The Qing Dynasty nationality is the "Chang Jianhua test system (" Social Science Journal "in 1989 fifth) that is designed to prevent the family clan, in separate family long beyond the use of real duty service. "On the policy and practice of Qianlong clan governance" ("academic" in 1990 second) discussed the family has prevent the expansion of the clan forces, is the essence of the Qing Dynasty to the clan governance tools, and further reflects the problems in the clan on the contradiction between ideal and reality. At the same time, Chang Jianhua in "some of the Qing Dynasty nationality is the problem" ("Qing Research Communications" in 1990 first) this family is having time and regional characteristics, try and media, and is thought to be the support of the Qing government and there is a growing popularity and the full implementation of the process. The family is made simply as the Qing government to strengthen the "clan" product ideas are clarified in this paper.

"The Qing Dynasty carried out filial piety clan system policy" ("history of the Ming and Qing Dynasties on" second sets, Tianjin ancient books publishing house in 1991), Chang Jianhua discusses 
policy support for the Qing Dynasty clan, filial piety of the world clan system brought the clan blood relationship and become strong, with strong maintenance of natural economy with blood, social organization and natural economy is greatly strengthened the social structure of the Qing Dynasty China. The role of Zhang Jinjun "the Qing Dynasty Jiangnan clan in rural social control" ("Journal of Anhwei Normal University " in May 2006) from the village control angle of Jiangnan clan function, discussed the overall point of view, the main auxiliary clan organization is also the national power control Jiangnan Rural Social forces, to maintain long-term stable development of the rural society of Jiangnan play an important role.

\section{Clan Field System}

Scholars generally believe that the clan cemetery has important social relief function, Yizhuang also has certain attributes of welfare institutions. "The Ming and Qing Dynasties clan social relief function of Hong Pu" ("Anhui history", 1997 fourth), more than the Xinzhong "of late Qing Dynasty, the squire's social relief -- Suzhou Feng Yu Yizhuang research" ("Journal of Nankai University 1997 third) introduced the Ming and Qing Dynasties clan social relief function. "On Yoshida in the late feudal society and its social function" ("social studies" in 1992 sixth) stressed Yoshida including blood as a link to the family, the blood and geopolitical ties to the clan, to tie the industry group and other social organizations in the economic foundation, and it is the economic foundation of the existence and stability of the family, such as the clan or industry group to play the role of stabilizing the feudal order.

On the welfare attribute of clan Yizhuang, fan Yao in "welfare" attributes of ancient Jiangnan clan cemetery ("Jiangnan forum" in September 2015) that, according to the existing literature, general historians will determine the source of the ancient clan cemetery in the Northern Song Dynasty Fan Zhongyan in Suzhou set up a fan's charity group. Zhang Zhanli "the Ming and Qing Dynasties clan system and basic social control" (Master's thesis, Shandong Normal University, 2010) demonstrated Yizhuang also not only relief agencies, largely in order to maintain the prestige of the family, such as semantics for the imperial examination, the remedy is to prevent the widow Yoshida widow remarried a disgrace to the common.

The song of Wang Shanjun "(" production "Chinese economic history research" in 1992 third) discusses the types, sources, production management and production management, national policy etc.. Liao Zhihao, Li Maogao "on Fan Zhongyan and van der Waals Yizhuang" ("academic monthly 1991 tenth) discussed the problem of fan's charity group. The Zhejiang area is generally considered the most popular families who have two, Yue worship production, Yue Xian ", and" strong home whenever analysis one or two dial the Cuan, what is the public property, as far as the number of acres from dozens of acres". Remove the household division generated public deposit, there are also many direct donation.

Song Ruiqi in "on the clan field in modern Zhejiang rent rate" ("China agricultural history" in June 2014) by Zhejiang genealogy and modern Zhejiang rural survey data analysis found that Zhejiang area family land rent rate is low. The low rent rate of clan fields promoted the growth of clans, and also caused damage to the rural areas of Zhejiang. According to the investigation and statistics of the East China military and Political Committee, the proportion of farmland occupied by the Fujian nationality is $29.36 \%$, Zhejiang is $16.35 \%$, Anhui is $4.17 \%$, and South of Jiangsu is $5.9 \%$. Zhejiang is the largest province in the Yangtze River Basin, with an average of 21571 mu per county. Song Ruiqi analysis due to the clan field sources, the Zhejiang area of clan field in the choice of rental tenants, it is different from the Jiangsu and Anhui regions, but people will become the preferred rental object. In order to ensure the continuous expansion of the clan field, and to enable ethnic groups to donate widely, the rent rate of the Tian nationality will not be too high. At the time of the Zhejiang area of worship production (clan fields) are a lot of people donated by myself, and then by the donor. Zhejiang is known as "seven mountains, one water and two fields". In the face of the siege and hostility of local indigenous people (or different views), as well as the competition and challenge of other tourists, it is necessary to protect the people and live in the country. 
"The college student Feng Erkang clan in Qing Dynasty and its historical significance" that is the construction of the family clan content. The clan in order to maintain and improve their social status, set up school schools, educational and other special funds and rely on public property, in the construction of schools, employment, the award for outstanding assistance, is the long-term support of special funds to the clan children to learn, is the material conditions of personnel training. The south is through transmission of talent to the court, the family closely combined with politics, it made "can not only prevent local officials can guarantee the receipt of breach of privilege, rent, and be able to intervene in local ruling power".

\section{Culture and Education}

As for the cultural education of the clans, many scholars studied the clan culture of the Jiangnan during the Ming and Qing dynasties. The culture of noble and Yan Dichang "(" Wuzhong literature "cultural and historical knowledge" in 1990 eleventh) mainly discusses the causes and characteristics of Jiangnan culture family, believe that the formation of Jiangnan culture of the family has its two internal and external factors, internal factors are the imperial examination system to stimulate and no disgrace to ken, not falling of common mind, external factors developed economy, education is booming and relatively stable regional social life environment. In the "hidden" mentality and culture of Ming and Qing Dynasties aristocracy "Wuzhong (" Journal of Soochow University 1991 first) in Yan Dichang to "hidden" mentality as the starting point to study the Wuzhong area of the Ming and Qing Dynasties aristocratic culture. Jiang Qingbai in the "South of Jiangsu family and family culture in Qing Dynasty" ("Qing finishing research" in 1999 second), "women" in the Ming and Qing Dynasties South of Jiangsu family ("traditional culture and modernization" in 1999 third) and "the Ming and Qing Dynasties South of Jiangsu family culture" (Nanjing Normal University press, 1999), the Ming and Qing Dynasties Jiangnan family culture is made a more comprehensive study, including the clan education during the Ming and Qing Dynasties Shanxi, Huizhou, Guangdong, Zhejiang jiang.

In terms of educational institutions and organizations, Wu Ni "family education" ("study area in the south of the Ming and Qing Dynasties China history research" in 1997 third) to explore two areas in the south of the Ming and Qing Dynasties, the purpose of education, family education. The history of interaction between the state and the local Lin Minxia ": clan culture and education organization perspective.Township School from the research history more than 100 years of change in late Qing Dynasty, discussed here in the process, the state power is how to implant the grass-roots social organizations and the role and shape the place; but also reveal the local initiative shown in this process, to change it to show the interaction of school in history and national history and local interaction. In the late Qing Dynasty and the Republic of China, in real life, in the following movement, the promotion of education and education is the main sponsor award.

Some scholars combine clan education with modern Chinese philosophy. Qiu Hansheng's "Neo Confucianism and patriarchal ideology" ("historical research" in 1979 eleventh) discusses the Song Mingli scientists to patriarchal discourse, family genealogy reflects the patriarchal system, the ancestral village and township school reading read about problems. In "on the Song Lian Han Wu clan thought" ("Oriental Studies" fourth series, Korea Research Institute of Oriental Studies, 1998) pointed out that the song's thought is proposed as a refinement of clan through education, governance clan, in order to transform the society, scholars should assume the surname of "pro in the United States the world custom task. This family governance thought has the teacher-student relationship and regional characteristics.

The development of clan culture was also influenced by political arguments. Yan Aimin "the" ritual "between the Ming Dynasty and the patriarchal ideology" ("Nankai history", 1991 first), from the patriarchal principle of the dispute, the right to worship the dispute, successive disputes, discusses the ritual in the patriarchal dispute, that ritual has led to significant changes in clan history, ancestors the patriarchal concept has become the most important principle, the most obvious temple built and chase Festival ancestor in folk activities become common. 


\section{Family Instructions}

Generally speaking, there is a difference between home and family, home is the family living together, with economic attribute is very strong, and it is mainly to blood as a complex link by multiple family composition; home and family appeared phenomenon is extremely rare, only the multigeneration family and nationality not only for you but, this is not much, not China ancient social norm.

The so-called "family law, it is no exaggeration to say, is nothing more than the religious identity on the relationship between them can be decomposed as said before his son, father, brother and other three kinds of relations in the cohabitation finances such field shows some rights such problems include family law family and clan regulations in two parts, the object law bundle was not household division family members, including belonging to this family of slaves et al, clan and clan constraints, generally does not involve the private family owned slaves. The content of family law mainly includes hierarchy, identity system, clan sacrifice, ethics, clan property relations, marriage, family and inheritance, etc.. Chinese ancient family law in law, written rules, instructions, home, home, home no moment, about family rules and discipline, about, about, Zongshi, Yizhuang rules and other forms.

According to the value and function of the clan, Cao Kai "on the value orientation and function China ancient family law" (Master's thesis, Heilongjiang University, 2011) that China ancient family law with affection, reason and law for the content, in pursuit of hoping to reach a harmonious order of good vision, in order to maintain stability and unity family; at the same time China ancient family law reflects the three functions of political, social and economic, reflects the positive interaction of home and country. Zhu Yong discussed the function of Jiangnan clan law in the economic function of the clan law of Jiangnan in Qing Dynasty (Chinese economic history study fourth) in 1987. The social role of his "the Qing Dynasty Jiangnan clan law" ("academic" in 1988 fourth) that the clan from the role of law can be divided into two categories, one is the maintenance of the state order, put in requirements members must in accordance with the national laws and fulfill their own obligations; two is to maintain the clans.

On the legal nature of the clan and its relationship with the law and the state law, Liu Guangan "historiography model -- read $<>$ " China family law principle "around the so-called Communist family" specializing in family life law. Chinese family law Ma Jing "multi perspective" (Master's thesis, Soochow University, 2011) based on discussing the necessity and rationality of family law popularization in the development of ancient history, the late family statute carried out and discusses its legal attribute. Analysis of the relationship between the China ancient family law and national law "Zou Yongming" (Master's thesis, Xiangtan University, 2007) that the ancient family law Chinese has strengthened the national criminal legislation, suppressed the citizen lawsuit consciousness, and to safeguard the harmonious order of the basic unit society makes a contribution.

\section{Conclusion}

Jinhua city hall area emerged in the Tang and song dynasties. At present, the earliest known ancestral hall is the ancestral hall of Yiwu temple, built in the Tang Dynasty. The Yuan Dynasty, the Jinhua region affected by the influence of Neo Confucianism in Song Dynasty Zhu Xi, the famous scientist in the four province Mr. (He Ji, Wang Bai, Jin Lvxiang, Xu Qian), the rapid development of folk shrine. During this period, Chinese scholars because of officialdom is not successful, then the construction began to keen on the ancestral hall. The Ming Dynasty, Pujiang Cheng hall has begun to form a strong social influence, Zhu Yuanzhang Zheng Zhaizong letter "Jiangnan first temple".

Zhejiang is the number of surviving the genealogical literature Dabang, Pang giant, preliminary statistics, at least 6000. Only one place in Jinhua, Lanxi from more than 900 kinds of Pujiang genealogy, genealogy of more than 300 species, more than 300 kinds of Dongyang genealogy, Wuyi genealogy genealogy of Yongkang has about 200 species, about 200 species, and Jinhua Tangxi genealogy is under 300, a total of more than 2000. Professor Huang Linggeng presided over the 
compilation of "Jinhua literature" is "a genealogical integrated part rebuilt Jinhua series", more than 490 genealogies were collected and compiled from the preface and postscript, celebrity tablets, funeral oration, biography, Ming Chan, biography, memoir, notes and poems for tens of thousands of articles, 20 books, the content is very rich, many data not found in his office. Compilers from a series of Song Lian Yi as more than 200 articles, Jin Lvxiang lost for more than 20 articles, Hu Han lost for more than 20 articles, Fang Yi made more than 40 articles, Su Boheng lost for more than 30 articles. Remarkable contains the historical and cultural value of Jinhua genealogy literature.

In May 22, 2015, the Commission website launched the "China tradition" rule first, the list is the pro Ming Taizu Zhu Yuanzhang gave "Jiangnan first", from Xiaoyi Chuan 900 years in Jinhua city Pujiang County Pujiang Zheng Yimen. Pujiang Zheng an, also to clean family fame in the world. From Southern Song Dynasty to the middle period of Ming Dynasty, there were fifteen living food, made "children live together in peace together, to have an official, but students cut dirty ink, except death spectrum nationality, no rules into the ancestral tablets". The 168 house rules, the Song Lian finishing zone to Nanjing played in court, the Ming Dynasty became the blueprint for the patent laws. Jiangnan first extension of the fifteen Xiaoyi world the secret lies in the 168 house rules. Following the Pujiang Zheng Yi door, Lanxi Zhuge Bagua village, Dongyang woodcarving Museum,

\section{References}

[1] Ma Xin. A Theory of Chinese Traditional Patriarchal Clan [J]. Journal of Shandong University (Philosophy and Social Sciences), 2015(4): 1-13.

[2] Jin Aning, Tian Yongquan, Chen Yanqiu. Operation Logic of the Internalized Confucian Culture in Patriarchal Clans [J]. Academics, 2014(5): 303-307.

[3] Cheng Jianxuan. Discourse Choice in Clan Management Dominated by Huizhou Patriarchal Clan [J]. Journal of Bengbu University, 2016, 5(4): 160-164.

[4] Wu Zukun, Wang Huishu. The Introspection on the Social Function of the Patriarchal Clanfromthe Perspective of Culture [J]. Journal of Renmin University of China, 2014(3): 132-139. 